\title{
OPEN Author Correction: Fibrinogen - A Practical and Cost Efficient Biomarker for Detecting Periprosthetic Joint Infection
}

\section{S. M. Klim, F. Amerstorfer, G. Gruber, G. A. Bernhardt, R. Radl, L. Leitner, A. Leithner \& M. Glehr}

Correction to: Scientific Reports https://doi.org/10.1038/s41598-018-27198-3, published online 11 June 2018

The original version of this Article contained errors as a result of an error caused during data transmission in which incorrect column conversion occurred leading to the reported mismatch in specificity outcomes.

As a result, in the Abstract,

"For fibrinogen, the value of $519 \mathrm{mg} / \mathrm{dl}$ had a sensitivity of 0.90 and a specificity of $0.34 . "$

now reads:

"For fibrinogen, the value of $519 \mathrm{mg} / \mathrm{dl}$ had a sensitivity of 0.90 and a specificity of $0.66 . "$

In the Biomarker Results section,

"For fibrinogen, a value of $573.5 \mathrm{mg} / \mathrm{dl}$ had a sensitivity of 0.81 and a specificity of 0.25 . The value of $519 \mathrm{mg} / \mathrm{dl}$ had a sensitivity of 0.90 and a specificity of 0.34 ."

now reads:

"For fibrinogen, a value of $573.5 \mathrm{mg} / \mathrm{dl}$ had a sensitivity of 0.81 and a specificity of 0.75 . The value of $519 \mathrm{mg} / \mathrm{dl}$ had a sensitivity of 0.90 and a specificity of 0.66 ."

Additionally, there was an error in the Material and Methods section where,

"We performed univariate logistic regressions and calculated non-linear mixed models with a first-order autoregressive covariance structure. Additionally, receiver operating characteristic curves (ROC curves) were plotted."

now reads:

"We performed univariate logistic regressions and plotted receiver operating characteristic curves (ROC curves)."

These errors have now been corrected in the PDF and HTML versions of the Article. 
(1) Open Access This article is licensed under a Creative Commons Attribution 4.0 International cc) License, which permits use, sharing, adaptation, distribution and reproduction in any medium or format, as long as you give appropriate credit to the original author(s) and the source, provide a link to the Creative Commons license, and indicate if changes were made. The images or other third party material in this article are included in the article's Creative Commons license, unless indicated otherwise in a credit line to the material. If material is not included in the article's Creative Commons license and your intended use is not permitted by statutory regulation or exceeds the permitted use, you will need to obtain permission directly from the copyright holder. To view a copy of this license, visit http://creativecommons.org/licenses/by/4.0/.

(C) The Author(s) 2020 